\title{
Human activity intensity of land surface: Concept, methods and application in China
}

\author{
XU Yong ${ }^{1}$, XU Xiaoren ${ }^{1,2}$, ${ }^{*}$ TANG Qing ${ }^{1}$ \\ 1. Institute of Geographic Sciences and Natural Resources Research, CAS, Beijing 100101, China; \\ 2. University of Chinese Academy of Sciences, Beijing 100049, China
}

\begin{abstract}
Human activity intensity is a synthesis index for describing the effects and influences of human activities on land surface. This paper presents the concept of human activity intensity of land surface and construction land equivalent, builds an algorithm model for human activity intensity, and establishes a method for converting different land use/cover types into construction land equivalent as well. An application in China based on the land use data from 1984 to 2008 is also included. The results show that China's human activity intensity rose slowly before 2000 , while rapidly after 2000 . It experienced an increase from $7.63 \%$ in 1984 to $8.54 \%$ in 2008. It could be generally divided into five levels: Very High, High, Medium, Low, and Very Low, according to the human activity intensity at county level in 2008, which is rated by above $27 \%, 16 \%-27 \%, 10 \%-16 \%, 6 \%-10 \%$, and below $6 \%$. China's human activity intensity was spatially split into eastern and western parts by the line of Helan Mountains-Longmen Mountains-Jinghong. The eastern part was characterized by the levels of Very High, High, and Medium, and the levels of Low and Very Low were zonally distributed in the mountainous and hilly areas. In contrast, the western part was featured by the Low and Very Low levels, and the levels of Medium and High were scattered in Gansu Hexi Corridor, the east of Qinghai, and the northern and southern slopes of Tianshan Mountains in Xinjiang.
\end{abstract}

Keywords: human activity intensity; land surface; construction land equivalent; land use/cover types; China

\section{Introduction}

Human activity is an objective existence in the process of social development. It is a concept with extensive contents, including all possible behaviors of human and can be classified in many ways (Ye et al., 2001). From the perspective of human's effects on nature, human activity can be defined as human's exploitation, utilization, and protection of natural environment for their own survival and development. Since the 1970s, the international scientific communities have paid great attention to human's influence on natural process (Liu et al., 2006; Miler, 1994; Shi et al., 2009). They launched the World Climate Research Program

Received: 2016-03-02 Accepted: 2016-04-06

Foundation: National Natural Science Foundation of China, No.41171449, No.41301121, No.41430636; The Key Research Program of the Chinese Academy of Sciences, No.KZZD-EW-06-01

Author: $\mathrm{Xu}$ Yong, Professor, specialized in human-environment interactions and regional development.

E-mail: xuy@igsnrr.ac.cn

*Corresponding author: Tang Qing, PhD, E-mail: tangq@igsnrr.ac.cn 
(Barry, 2003; IPCC, 2014), the International Geosphere-Biosphere Program (Leemans et al., 2009; Mauser et al., 2013), the International Human Dimensions Program (Jager, 2003) and the Biodiversity Plan (Loreau and Olivieri, 1999). All these plans considered the influences of human activities and noticed the characteristics of land cover of land surface, which was influenced by both natural processes and human activities (Turner et al., 1995).

In 1996, Land Use/Cover Change (LUCC) Scientific Research Program was initiated to reveal the interaction between the environmental systems and human production systems on the earth, including agriculture, industrialization, urbanization, etc (Fresco et al., 1996; Li, 1996). LUCC is one of the main causes of global change, and it is the issues most closely related to natural and human processes, affecting the sustainable development of cities, societies and people's daily lives (Gao et al., 2015; Mottet et al., 2006). Economic and social factors were considered in the study of causes, mechanism, driving forces, and model building (Liu and Deng, 2009; Pelorosso et al., 2009; Tang et al., 2009). Recently, land change science has emerged as a fundamental component of global environmental change and sustainability research (Turner et al., 2007). As much as half of the earth's ice-free land surface has been transformed by human activities (Haberl et al., 2007; Vitousek et al., 1997). It is widely speculated that modifying roughly $50 \%$ of all land is the biggest human-caused threat to biodiversity (McGill, 2015). The global and regional impact of land use change on the coupled human-environment system needs to be thoroughly assessed.

Nevertheless, some researchers realized the defects that LUCC was studied only by adopting one-dimensional indexes, including cultivation index, land development intensity and output per unit area, etc. (Fan and Li, 2009; GOSC, 2010). They attached importance to integrated research of the comprehensive indexes. According to the natural balanced state of the land natural complex affected by social factors, the synthesis indexes of land use degree were acquired by weighted and summed area (Xu et al., 2009; Zhuang and Liu, 1997). To some degree, synthesis index reflects the extent of human activities on land surface, and the academic significance is the framework that the synthesis index is determined in terms of characteristics of land use types. However, the degree of land use is classified roughly and its classification parameters are on an inadequate basis (Zhu and Li, 2003). The expression of the index value has not been widely recognized.

From the perspective of the ecological environmental problems caused by human activities, some young scholars established comprehensive index system of human activities and carried out evaluation research. Wen first studied the concept of human activity intensity and its quantification (Wen, 1998). Index weights were determined by hierarchical analysis or expert scoring method. In the end, human activity intensity was calculated by weighted and summed indexes. Later this method was improved by Li Xiangyun, Zhang Cuiyun, Hu Zhibing, and so on. They were engaged in empirical application research in the northwestern arid area (Li et al., 2004; Wang et al., 2013; Zhang and Wang, 2004), the upper reaches of Minjiang River (Hu et al., 2007), Hutuo River Basin (Wang et al., 2009) and the southern hilly region of red soil (Zheng et al., 2010). The advantages of this method are strong pertinence on problems and unique local characteristics. The deficiencies are its broad concept and index selection varying from place to place. Moreover, the physical meanings of comprehensive indexes are not clear and it's not convenient to make interregional contrast.

Although the comprehensive research of human activity intensity has made some progress, 
researchers have not yet formed such comprehensive index algorithms as Ecological Footprint (Rees, 2001; Wackernagel and Rees, 1997) and Global Warming Potential (Sekiya and Okamoto, 2010) which have strong universality and are widely used. This paper tries to learn from Ecological Footprint and Global Warming Potential on their academic ideas and research framework. From the perspective of the relationship between land use/cover and human activity, comprehensive indexes of human activity intensity are built to reflect the effect and influence of human activities on land surface objectively, including concept definition, key parameters to be determined, model building, empirical application, etc. We expect that this study could strengthen the comparability of related research results at regional, national and global levels, and provide a parameter or indicator for the comprehensive research of global environmental change.

\section{Concepts and methods}

Land use and land cover are two concepts describing land surface status. Currently, it is widely agreed in academia that land use is the comprehensive reflection of resources and natural environment on land surface influenced by human economic and social activities. It is the result of interaction between human activities and natural process (Wu and Guo, 1994). Due to different research perspectives, there are some differences in defining land cover. IGBP and IHDP define land cover as the natural state of land surface and ground layer (Turner et al., 1995), and the result of interaction between human activities and natural process. USSGCR regards it as the vegetation covering land surface and other characteristics (US-SGCR/CENR, 1996). Graetz considers land cover to be the rolling land surface covered with vegetation, snow, ice or water, the soil layer included (Graetz, 1993). In general, land cover can be defined as the complex of all key elements of surface covered by natural and artificial buildings, including vegetation, soil, lakes, marshes, and various kinds of buildings. Therefore, the two concepts have close relation, but there is difference. Li Xiubin (1996) believes that land use is the most important factor affecting the land cover, while the change of the latter, in turn, acts on the former.

Based on the perspective of the land use/cover concept, human activity intensity of land surface is defined as the degree of natural cover use, transformation and exploitation of land surface by human in a certain region. This degree can be reflected by land use/cover types. Obviously, human activity intensity of land surface belongs to the conceptual category of the general human activity intensity, which refers to the influence of economic and social activities on a certain regional natural complex. The use, transformation, exploitation of land surface can be seen as the main body of human activity, but not the whole. Human activity intensity of land surface can be expressed as:

$$
\begin{gathered}
H A I L S=\frac{S_{\mathrm{CLE}}}{S} \times 100 \% \\
S_{C L E}=\sum_{i=1}^{n}\left(S L_{i} \times C I_{i}\right)
\end{gathered}
$$

where HAILS is human activity intensity of land surface; $S_{C L E}$ is the area of construction land equivalent; $S$ is the total land area; $S L_{i}$ is the area of land use/cover type $i ; C I_{i}$ is conversion coefficient of type $i$ for construction land equivalent; $n$ is the numbers of land 
use/cover types.

Construction land equivalent (CLE) is used to compare effects on land surface by different human activities and is reflected by land use/cover types. Construction land is regarded as a land use/cover type with the strongest effects of human activities. So construction land equivalent is stipulated as the basic unit to unify the measure of the effects on land surface.

Conversion coefficient of land use/cover type for construction land equivalent means converting the effects on land surface by human activities into construction land equivalent. Different land use/cover types reflect diverse degree of land use, transformation, and exploitation by human. "Use" refers to the use of the surface, but the attributes of the natural cover do not change, such as grassland. Transformation means that the natural cover changes, but water, nutrient, air and heat exchange normally, such as garden plot and farmland. Exploitation indicates that artificial insulation layers are added to the surface, leading to the block of the water, nutrient, air and heat exchange, such as reservoir and construction land. The change of natural attributes above can be used to determine the conversion coefficient of construction land equivalent by the following two-level algorithm step by step:

(1) At the first level, 0 is set for the eigenvalue whose natural attributes do not change and natural cover has not been used. 1 is set for those surfaces that have artificial insulation layers and where water, nutrient, air and heat exchange are blocked. Five equal parts are divided between 0 and 1 , marked by such characteristics as change of natural cover and the exchange of water, nutrient, air and heat. The eigenvalue corresponding to each characteristic sign is 0.2 . The corresponding value with the superposition of several characteristic signs is multiples of 0.2 .

(2) At the second level, 3 equal parts are divided between 0 and 0.2 , marked by the surface natural cover unchanged but used, natural cover changed and perennial planted, natural cover changed and annual crops planted, respectively. The degree of natural change is incremental. When the natural cover is unchanged but used, its eigenvalue is 0.067 . Under the second circumstance above, it is 0.133 . The last value is 0.2 with natural cover changed and annual crops planted.

The above eight characteristic signs and their corresponding eigenvalues are the fundamental basis for determining the conversion indexes of different land use/cover types for construction land equivalent (Table 1). But in the particular calculation process, special attention should be paid to the relationship and difference between the five feature signs at the first level and the three at the second level. The two levels interrelate through natural cover change at the first level and land cover change with annual crops at the second level. Consequently, both of the corresponding eigenvalues are 0.2 . The characteristic signs at the first level are higher than that at the second level. Three characteristic signs in the second level belong to natural cover change in the first one. The eigenvalues at the first level are independent and could accumulate in the calculation. The eigenvalues in the second level are incremental. The maximum among the 3 values should be selected in the calculation. The conversion coefficient for construction land equivalent is calculated as follows:

$$
\begin{gathered}
C I_{i}=F C S 1_{i}+F C S 2_{i}+F C S 3_{i}+F C S 4_{i}+F C S 5_{i} \\
F C S 1_{i}=\max \left(C S 1_{i}, C S 2_{i}, C S 3_{i}\right)
\end{gathered}
$$

where $F C S 1_{i}, F C S 2_{i}, F C S 3_{i}, F C S 4_{i}$ and $F C S 5_{i}$ are the corresponding values at the first level 
for land use/cover type $i$, respectively; $C S 1_{i}, C S 2_{i}$, and $C S 3_{i}$ are the corresponding values at the second level for land use/cover type $i$, respectively. With this method, conversion coefficients of the construction land equivalent are given in Table 2.

Table 1 Characteristic signs and corresponding eigenvalues of land surface

\begin{tabular}{|c|c|c|c|}
\hline Level & Category & Characteristic signs & Eigenvalue \\
\hline & & Natural cover of land surface does not change and is not used. & 0 \\
\hline \multirow{3}{*}{$\begin{array}{l}\text { The } \\
\text { second } \\
\text { level }\end{array}$} & $\mathrm{CS} 1$ & Natural cover of land surface does not change but is used. & 0.067 \\
\hline & $\mathrm{CS} 2$ & Natural cover of land surface changes and perennials are planted. & 0.133 \\
\hline & $\mathrm{CS} 3$ & Natural cover of land surface changes and annual crops are planted. & 0.2 \\
\hline \multirow{6}{*}{$\begin{array}{l}\text { The } \\
\text { first } \\
\text { level }\end{array}$} & FCS1 & Natural cover of land surface changes. & 0.2 \\
\hline & FCS2 & $\begin{array}{l}\text { There are artificial insulation layers on the surface. Water could be } \\
\text { exchanged. The exchanges of nutrient, air and heat are blocked. }\end{array}$ & 0.2 \\
\hline & FCS3 & $\begin{array}{l}\text { There are artificial insulation layers on the surface. Nutrient could } \\
\text { be exchanged. The exchanges of water, air and heat are blocked. }\end{array}$ & 0.2 \\
\hline & FCS4 & $\begin{array}{l}\text { There are artificial insulation layers on the surface. Air could be } \\
\text { exchanged. The exchanges of water, nutrient and heat are blocked. }\end{array}$ & 0.2 \\
\hline & FCS5 & $\begin{array}{l}\text { There are artificial insulation layers on the surface. Heat could be } \\
\text { exchanged. The exchanges of water, air and nutrient are blocked. }\end{array}$ & 0.2 \\
\hline & & $\begin{array}{l}\text { There are artificial insulation layers on the surface. The exchanges } \\
\text { of water, nutrient, air and heat are blocked. }\end{array}$ & 1 \\
\hline
\end{tabular}

Table 2 Conversion coefficients of different land use/cover types for construction land equivalent

\begin{tabular}{|c|c|c|c|}
\hline & Land use/cover types & Explanations of characteristic signs & $\mathrm{CI}$ \\
\hline Farmland & $\begin{array}{l}\text { Irrigated paddy field/rained paddy } \\
\text { field/irrigable land/dry land/vegetable land }\end{array}$ & $\begin{array}{l}\text { Natural cover of land surface changes and } \\
\text { annual crops are planted. }\end{array}$ & 0.2 \\
\hline Garden plot & $\begin{array}{l}\text { Orchard/mulberry field/tea garden/ rubber } \\
\text { plantation/other gardens }\end{array}$ & $\begin{array}{l}\text { Natural cover of land surface changes and } \\
\text { perennials are planted. }\end{array}$ & 0.133 \\
\hline \multirow[t]{3}{*}{ Forest land } & Closed forest land/shrub land/forestland & $\begin{array}{l}\text { Natural cover of land surface does not } \\
\text { change and is not used. }\end{array}$ & 0 \\
\hline & Young afforested land/nursery & $\begin{array}{l}\text { Natural cover of land surface changes and } \\
\text { perennials are planted }\end{array}$ & 0.133 \\
\hline & Cut-over land & Natural cover of land surface changes & 0.2 \\
\hline \multirow[t]{2}{*}{ Grassland } & Natural grassland/improved grassland & $\begin{array}{l}\text { Natural cover of land surface does not } \\
\text { change but is used. }\end{array}$ & 0.067 \\
\hline & Tame pasture & $\begin{array}{l}\text { Natural cover of land surface changes and } \\
\text { perennials are planted. }\end{array}$ & 0.133 \\
\hline \multirow[t]{3}{*}{$\begin{array}{l}\text { Other agri- } \\
\text { cultural land }\end{array}$} & Livestock and poultry breeding land & $\begin{array}{l}\text { There are artificial insulation layers on the } \\
\text { surface. The exchanges of water, nutrient, } \\
\text { air and heat are blocked. }\end{array}$ & 1 \\
\hline & $\begin{array}{l}\text { Land for protected agriculture / country } \\
\mathrm{road} / \text { riser of terrace }\end{array}$ & Natural cover of land surface changes. & 0.2 \\
\hline & Aquiculture area/pond & $\begin{array}{l}\text { Natural cover of land surface does not } \\
\text { change but is used. }\end{array}$ & 0.067 \\
\hline \multirow[t]{2}{*}{$\begin{array}{l}\text { Residential, } \\
\text { industrial, and } \\
\text { mining land }\end{array}$} & $\begin{array}{l}\text { Urban land/town area/rural residential } \\
\text { area/independent industrial and mining } \\
\text { land/land for special use }\end{array}$ & $\begin{array}{l}\text { There are artificial insulation layers on the } \\
\text { surface. The exchanges of water, nutrient, } \\
\text { air and heat are blocked. }\end{array}$ & 1 \\
\hline & Salt pan & $\begin{array}{l}\text { Natural cover of land surface changes. The } \\
\text { exchanges of air and heat are blocked. }\end{array}$ & 0.6 \\
\hline
\end{tabular}


(Continued)

\begin{tabular}{llll}
\hline & Land use/cover types & Explanations of characteristic signs & CI \\
\hline $\begin{array}{l}\text { Land for } \\
\text { transportation } \\
\text { port/port and pier/pipeline transport }\end{array}$ & $\begin{array}{l}\text { Land for railway/highway land/civil air- } \\
\text { Land for } \\
\begin{array}{l}\text { water facili- } \\
\text { ties }\end{array}\end{array}$ & $\begin{array}{l}\text { There are artificial insulation layers on the } \\
\text { surface. The exchanges of water, nutrient, } \\
\text { air and heat are blocked. }\end{array}$ & 1 \\
& Reservoir & $\begin{array}{l}\text { There are artificial insulation layers on the } \\
\text { surface. The exchanges of water, nutrient, } \\
\text { air and heat are blocked. } \\
\text { Natural cover of land surface changes. The } \\
\text { exchanges of air and heat are blocked. }\end{array}$ & 1 \\
\hline Unused land & $\begin{array}{l}\text { Wild grass ground/sand/bare rock gravel } \\
\text { land/saline-alkali soil/marsh land/barren } \\
\text { land }\end{array}$ & $\begin{array}{l}\text { Natural cover of land surface does not } \\
\text { change and is not used. }\end{array}$ & 0 \\
\hline $\begin{array}{l}\text { Other unused } \\
\text { land }\end{array}$ & $\begin{array}{l}\text { River/lake/reed/intertidal zone/glaciers and } \\
\text { permanent snow }\end{array}$ & $\begin{array}{l}\text { Natural cover of land surface does not } \\
\text { change and is not used. }\end{array}$ & 0 \\
\hline
\end{tabular}

\section{Results}

\subsection{Change of human activity intensity at national and provincial levels}

According to the land use data in China from 1984 to 2008, this paper calculates the national area of construction land equivalent and human activity intensity as shown in Figure 1. The human activity intensity change of provincial units is illustrated in Table 3. They present the following characteristics:

(1) The construction land equivalent area and human activity intensity in China rose slowly from 1984

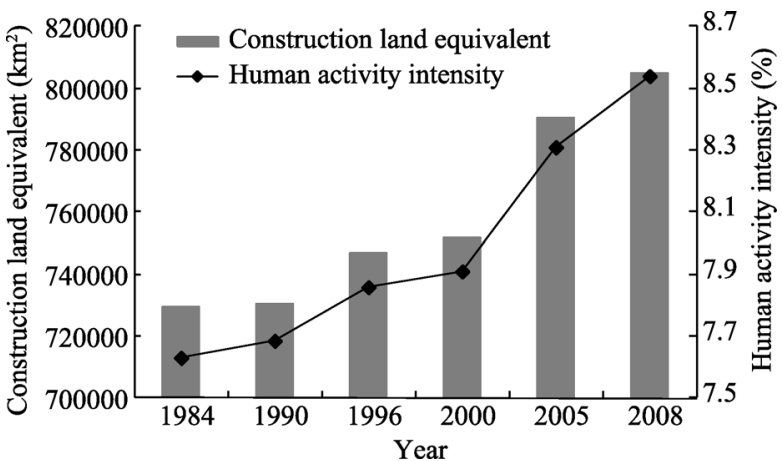

Figure 1 Changes of construction land equivalent area and human activity intensity of China in 1984-2008 to 2000 , while rapidly after 2000 . The total construction land equivalent area increased from $72.96 \times 10^{4} \mathrm{~km}^{2}$ in 1984 to $80.51 \times 10^{4} \mathrm{~km}^{2}$ in 2008 . During the 24 years, the average increment was $3145 \mathrm{~km}^{2} / \mathrm{y}$. The average increment in the early stage was 1401 $\mathrm{km}^{2} / \mathrm{y}$, and increased dramatically to $6634 \mathrm{~km}^{2} / \mathrm{y}$ in the late stage. The human activity intensity grew from $7.63 \%$ in 1984 to $8.54 \%$ in 2008 . During the 24 years, it increased by $0.91 \%$. The average growth rate per year in the early stage was below $0.02 \%$, but increased to $0.08 \%$ in the late stage.

(2) Human activity intensity at provincial level changed diversely. In the eastern coastal areas, it increased quickly, but the growth rate was small in the western regions. There was decrease in some individual provinces. During the 24 years, Shanghai and Tianjin had the greatest change, increasing by $20.58 \%$ and $12.6 \%$, respectively. The following were Beijing, Guangdong, Shandong, Zhejiang, and Jiangsu, increasing by $6.06 \%, 5.39 \%, 5.31 \%, 4.92 \%$ and $4.67 \%$ respectively. The increments of Anhui, Hunan, Hubei, and Henan were between $2 \%$ and $3 \%$. All other provinces were below $2 \%$. Shanxi and Shaanxi had negative growth, 
decreasing by $0.84 \%$ and $0.4 \%$, respectively, which were caused by returning farmland to forest and reclamation in mining districts. In addition, there existed slight fluctuation in parts of the provincial units.

Table 3 Changes of human activity intensity of China's land surface by provinces in 1984-2008 (\%)

\begin{tabular}{|c|c|c|c|c|c|c|c|}
\hline Provincial unit & 1984 & 1990 & 1996 & 2000 & 2005 & 2008 & $\begin{array}{l}\text { Changes during } \\
\text { the } 24 \text { years }\end{array}$ \\
\hline Shanghai & 25.73 & 33.57 & 33.57 & 35.79 & 39.14 & 46.30 & 20.58 \\
\hline Tianjin & 27.46 & 29.47 & 29.65 & 30.36 & 38.44 & 40.06 & 12.60 \\
\hline Jiangsu & 25.03 & 24.22 & 24.64 & 25.26 & 29.26 & 29.69 & 4.67 \\
\hline Shandong & 22.80 & 24.36 & 25.26 & 25.70 & 27.58 & 28.12 & 5.31 \\
\hline Beijing & 18.42 & 19.52 & 20.61 & 21.03 & 23.64 & 24.48 & 6.06 \\
\hline Henan & 21.79 & 22.91 & 23.43 & 23.58 & 23.71 & 23.91 & 2.13 \\
\hline Anhui & 19.20 & 19.23 & 19.75 & 19.89 & 21.90 & 22.16 & 2.96 \\
\hline Hebei & 16.49 & 16.70 & 17.08 & 17.35 & 17.33 & 17.72 & 1.24 \\
\hline Liaoning & 15.02 & 14.69 & 15.07 & 15.26 & 15.89 & 16.04 & 1.02 \\
\hline Chongqing & 14.19 & 12.85 & 13.00 & 13.29 & 15.02 & 15.19 & 1.01 \\
\hline Zhejiang & 9.93 & 10.59 & 11.08 & 11.41 & 13.93 & 14.85 & 4.92 \\
\hline Guangdong & 9.07 & 10.14 & 11.33 & 11.87 & 14.10 & 14.45 & 5.39 \\
\hline Hainan & 12.77 & 12.34 & 13.04 & 13.25 & 14.51 & 14.27 & 1.50 \\
\hline Hubei & 11.62 & 11.72 & 11.87 & 11.95 & 13.90 & 14.10 & 2.47 \\
\hline Shanxi & 12.94 & 11.78 & 11.86 & 11.93 & 11.95 & 12.10 & -0.84 \\
\hline Jilin & 10.86 & 11.88 & 11.79 & 11.84 & 11.95 & 12.03 & 1.16 \\
\hline Ningxia & 11.50 & 11.60 & 11.90 & 12.44 & 11.75 & 11.94 & 0.44 \\
\hline Hunan & 8.80 & 9.40 & 9.58 & 9.69 & 11.53 & 11.72 & 2.92 \\
\hline Guizhou & 8.40 & 9.18 & 9.11 & 9.09 & 10.09 & 10.16 & 1.76 \\
\hline Jiangxi & 9.46 & 7.78 & 8.04 & 8.15 & 9.57 & 9.82 & 0.36 \\
\hline Shaanxi & 9.99 & 10.28 & 10.28 & 10.12 & 9.55 & 9.59 & -0.40 \\
\hline Heilongjiang & 9.13 & 9.01 & 9.06 & 9.09 & 9.40 & 9.16 & 0.03 \\
\hline Sichuan & 8.38 & 7.76 & 7.92 & 8.00 & 8.70 & 8.76 & 0.38 \\
\hline Fujian & 8.42 & 6.26 & 6.85 & 7.12 & 8.18 & 8.60 & 0.19 \\
\hline Guangxi & 8.27 & 7.16 & 7.33 & 7.48 & 8.33 & 8.49 & 0.22 \\
\hline Gansu & 7.24 & 7.20 & 7.24 & 7.23 & 7.46 & 7.48 & 0.24 \\
\hline Yunnan & 5.68 & 5.73 & 5.78 & 5.86 & 6.56 & 6.65 & 0.97 \\
\hline Inner Mongolia & 6.24 & 6.63 & 6.72 & 6.52 & 6.38 & 6.43 & 0.18 \\
\hline Qinghai & 3.53 & 4.28 & 4.34 & 4.34 & 4.94 & 4.40 & 0.86 \\
\hline Tibet & 3.71 & 3.70 & 3.70 & 3.70 & 3.63 & 3.73 & 0.02 \\
\hline Xinjiang & 3.28 & 3.02 & 3.22 & 3.25 & 3.35 & 3.37 & 0.09 \\
\hline China & 7.63 & 7.69 & 7.86 & 7.91 & 8.31 & 8.54 & 0.91 \\
\hline
\end{tabular}


(3) There existed great differences in human activity intensity among provinces. In the period of 1984-2008, the difference had an expanding trend. According to the spatial distribution of human activity intensity at the provincial level (Figures 2 and 3), there were five provinces where human activity intensity was above $20 \%$ in 1984, including Tianjin, Shanghai, Jiangsu, Shandong, and Henan. Beijing and Anhui were added in 2008. It was between $13 \%$ and $20 \%$ in Beijing, Anhui, Liaoning, Hebei and Chongqing in 1984. Zhejiang, Hubei, Guangdong and Hainan were added in 2008. It was below 5\% in Xinjiang, Tibet and Qinghai. Human activity intensity was between $5 \%-13 \%$ in other provinces. Tianjin had the highest human activity intensity, whereas Xinjiang had the lowest in 1984. They were $27.46 \%$ and $3.28 \%$ respectively. In 2008, Shanghai had the highest human activity intensity (46.30\%), which was nearly $43 \%$ higher than that of Xinjiang.

\subsection{Spatial differentiation of human activity intensity}

According to the land use change data at county level in 2008, this paper used

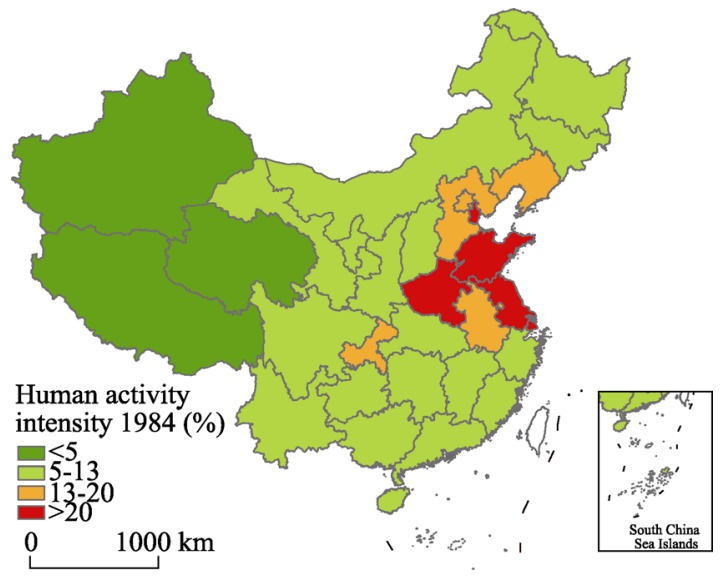

Figure 2 Differences of human activity intensity of China's land surface by provinces in 1984

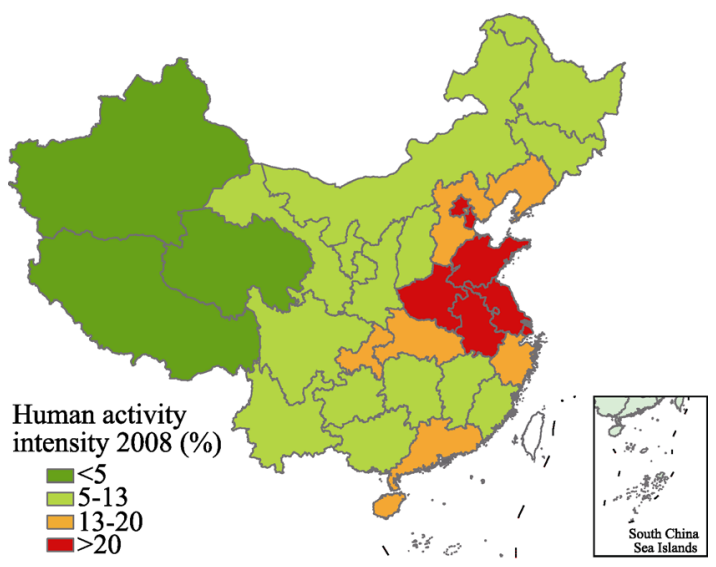

Figure 3 Differences of human activity intensity of China's land surface by provinces in 2008 county-level administrative map of 2004 as the spatial unit and calculated human activity intensity of each unit so that their spatial characteristics of land surface could be revealed more clearly. Using GIS and the method of natural fracture, human activity intensity by counties could be divided into five levels including Very High, High, Medium, Low, and Very Low, rating by above $27 \%, 16 \%-27 \%, 10 \%-16 \%, 6 \%-10 \%$, and below $6 \%$. The results and its spatial distribution were shown in Table 4 and Figure 4.

Table 4 Classification of human activity intensity of China's land surface by counties in 2008

\begin{tabular}{ccccc}
\hline Type & Grading standard (\%) & Number & $\begin{array}{c}\text { Average human } \\
\text { activity intensity (\%) }\end{array}$ & $\begin{array}{c}\text { Average area of construction } \\
\text { land equivalent }\left(\mathrm{km}^{2}\right)\end{array}$ \\
\hline Very High & $>27$ & 487 & 32.52 & 341.78 \\
High & $27-16$ & 478 & 20.99 & 361.50 \\
Medium & $16-10$ & 459 & 12.43 & 310.07 \\
Low & $10-6$ & 493 & 7.56 & 323.28 \\
Very Low & $<6$ & 458 & 3.29 & 342.01 \\
\hline
\end{tabular}


The human activity intensity in China was spatially split into eastern and western parts by the line of Helan Mountains-Longmen Mountains-Jinghong in 2008 (see the blue dashed line in Figure 4). Human activity intensity was high in the eastern part, while it was low in the western part. The eastern part was characterized by the levels of Very High, High, and Medium, and human activity intensity of Low and Very Low levels were zonally distributed in mountainous and hilly regions. The western part was featured by the Low and Very Low levels. There ex-

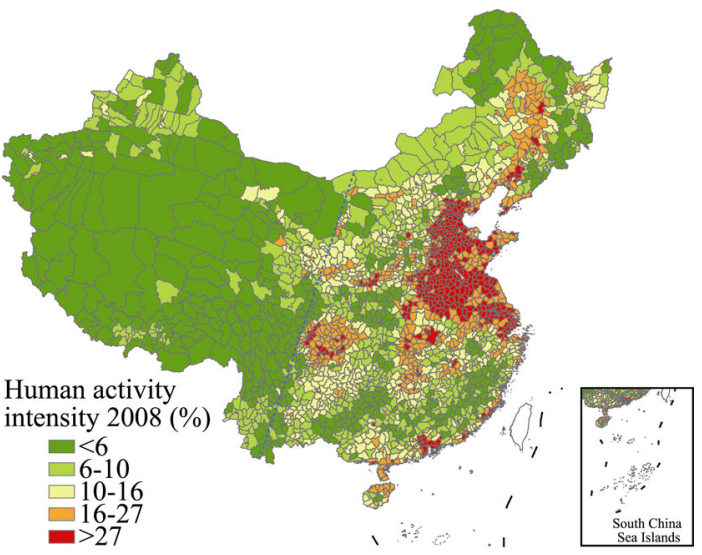

Figure 4 Spatial differences of human activity intensity of China's land surface by counties in 2008 isted scattered types of Medium and High in Hexi Corridor in Gansu, the loess plateau in the east of Qinghai, northern and southern slopes of Tianshan Mountains in Xinjiang. The characteristics and spatial distribution of each level were as follows:

(1) Very High level. Human activity intensity was above $27 \%$. There were 487 county units, where the average construction land equivalent was $341.78 \mathrm{~km}^{2}$. The average human activity intensity of the units was $32.52 \%$. The concentrated distribution areas were the Huang-Huai-Hai Plain, the Yangtze River Delta and the Pearl River Delta, and the scattered areas were such urban agglomerations as Sichuan Basin, middle reaches of the Yangtze River, the Northeast China Plain, the southeast coastal zone and Fenhe-Weihe river valley.

(2) High level. Human activity intensity was between $16 \%$ and $27 \%, 478$ county units included. The average construction land equivalent of the units was $361.5 \mathrm{~km}^{2}$, and the average human activity intensity was $20.99 \%$. Their distribution trend was consistent with that of Very High level, whereas they were distributed in a large scale in the Northeast China Plain, Liaodong Peninsula, Shandong Peninsula, the middle and lower reaches of the Yangtze River, Sichuan Basin, Fenhe-Weihe river valley, the middle and east of Gansu, Hetao Plain of the Yellow River, Leizhou Peninsula, the northeast of Hainan Island, etc.

(3) Medium level. The human activity intensity was between $10 \%$ and $16 \%$. There were 459 county units. The average construction land equivalent was $310.07 \mathrm{~km}^{2}$, and the average human activity was $12.43 \%$. They were distributed around the High level areas, such as the western Loess Plateau, Sanjiang Plain and Yunnan-Guizhou Plateau.

(4) Low level. Human activity intensity was between $6 \%$ and 10\%, 493 county units included. The average construction land equivalent was $323.28 \mathrm{~km}^{2}$, and the average human activity intensity was $7.56 \%$. To the west of the line of Helan Mountains-Longmen Mountains-Jinghong, north of the Tianshan Mountains, the Loess Plateau in the east of Qinghai, southwestern Yunnan and areas along the Yarlung Zangbo River and two other rivers of Tibet were parts of the Low level. In the east of the line, its distribution trend was in accordance with that of Very Low level, except the middle and east of Inner Mongolia.

(5) Very Low level. Human activity intensity was below 6\%. There were 458 county units. The average construction land equivalent was $342.01 \mathrm{~km}^{2}$, and the average human activity 
intensity was $3.29 \%$. In the west of the line of Helan Mountains-Longmen Mountains-Jinghong, the southern Tianshan Mountains, Alxa League in Inner Mongolia, the west of Sichuan and the northwestern Yunnan were parts of the above areas. In the east of the line, the Very Low level areas were mainly mountains and hills, including Greater and Lesser Hinggan Mountains-Changbai Mountains, Yanshan Mountains-Taihang Mountains, loess hilly-gully areas, Qinling-Daba Mountains, Wuling mountainous area, etc.

\section{Discussion}

There are different ways to describe human activity intensity of land surface. This paper takes the ratio of construction land equivalent area to the total land area to delineate human activity intensity, emphasizing its total ratio and spatial differentiation. Construction land area equivalent per capita could also be adopted to describe the concept. This expression could compare human activity intensity in different regions from the perspective of "per capita occupancy".

Human activity intensity correlates with the population density. The correlation analysis between human activity intensity and population density could verify the feasibility and effectiveness of human activity intensity measurement methods from one side. By matching human activity intensity of the 2365 counties with the corresponding population data in 2008, this study finds out that there exists exponential function relationship between them (Figure 5). The correlation coefficient is 0.8156, indicating that the expression and measurement methods of human activity intensity are feasible and effective. The fitting exponential function could be expressed as follows.

$$
\begin{gathered}
\text { HAILS }=1.5045 X^{0.4036} \\
R^{2}=0.6652
\end{gathered}
$$

The conversion coefficients of different land use/cover types for construction land equivalent are determined by the following four steps. The first step is level division based on whether there exist artificial insulation layers of non-primary production on the surface. Those with insulation layers belong to the first level, while those without belong to the second one. The second step is to explore characteristic signs used as quantitative basis. By studying different types of construction land, rainfall infiltration and water environment effect (Hou et al., 2006; Liu et al., 2011; Zhu et al., 2009), whether natural cover of surface changes, its water, nutrient, air and heat exchanges are thought as the five characteristic signs in the first level. By analyzing soil nutrients and water infiltration (She et al., 2014; Wang et al., 2003; Yu et al., 2014), three characteristic signs in the second level including natural cover unchanged but used, changed natural cover with perennials, changed natural cover with annual plants, are determined. In the third step, this study refers to the ideas of quantitative classification of land use by Liu Jiyuan (Xu et al., 2009; Zhuang and Liu, 1997). According to the principle that attributes are equally important, five characteristic signs in the first level are used to divide 1 into five equal parts. Three characteristic signs in the second level are utilized to divide 0.2 into three equal parts. Finally, based on the eight eigenvalues, conversion coefficients of different land use/cover types for construction land equivalent are determined by correspondence relation. 
Problems remain to be further discussed. When this paper presents the concept of human activity intensity and its measurement method, it does not consider the following problems: the aggravation of water loss and soil erosion caused by steep slope reclamation, grassland degradation brought about by overgrazing, the deterioration of the environment led by energy-intensive and pollution-high industrial technology, land subsidence caused by groundwater overexploitation, "urban disease"

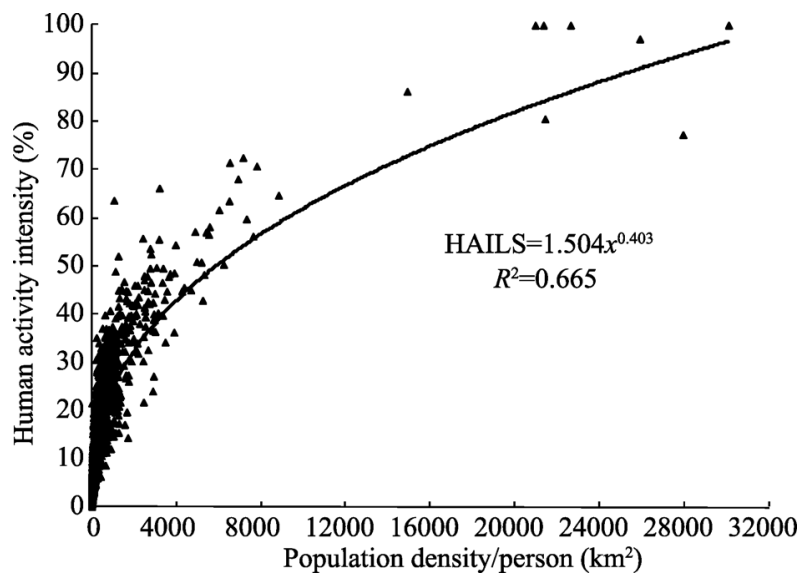

Figure 5 Correlation between human activity intensity and population density by counties in China in 2008 resulting from urban spreading expansion. The "suitability" of human activity intensity involving regional characteristics of natural environment, endowment of resources and development level of technology and economy, is not taken into account. In particular areas, reasonable way of human activity and appropriate human activity intensity need to be studied in the future.

\section{Conclusions}

The results show that it is accurate to define human activity intensity as the degree of natural cover use, transformation and exploitation of land surface by human beings, and it is an effective method to determine the conversion coefficients of different land use types for construction land equivalent by the characteristic signs of natural attribute change caused by human activity. The application and the correlation analysis between human activity intensity and population density indicate that it is feasible to take the ratio of construction land equivalent area to the total area as an indicator of human activity intensity.

Based on natural attribute change of land surface caused by land use, transformation and exploitation, this paper adopts a two-level and eight-eigenvalue method to determine general standard of converting different land use/cover types into construction land equivalent, and presents a method for calculating the conversion coefficients for construction land equivalent. It also builds a coefficient table for construction land equivalent of 49 land use types based on the latest land use classification system in China.

The human activity intensity in China has rapidly increased since the year of 2000, from $7.63 \%$ in 1984 to $8.54 \%$ in 2008 . Human activity intensity at provincial level changed diversely. In the eastern coastal areas, it increased sharply, but the changing rate was small in the western regions. There was a slight decrease in Shanxi and Shaanxi.

Human activity intensity could be divided into five levels including Very High, High, Medium, Low, and Very Low, according to the human activity intensity at county level in 2008 , which was rating by above $27 \%, 16 \%-27 \%, 10 \%-16 \%, 6 \%-10 \%$ and below $6 \%$. The human activity intensity in China was spatially split into eastern and western parts by the line of Helan Mountains-Longmen Mountains-Jinghong. Human activity intensity was high 
in the eastern part, while it was low in the western part. The eastern part was characterized by the levels of Very High, High, and Medium. Human activity intensity at Low and Very Low levels had zonal distribution in its mountainous and hilly areas. The western part was featured by the Low and Very Low level. There existed scattered types of Medium and High in Hexi Corridor in Gansu, the Loess Plateau in the east of Qinghai, and northern and southern slopes of the Tianshan Mountains in Xinjiang.

\section{References}

Barry R G, 2003. Mountain cryospheric studies and the WCRP climate and cryosphere (CliC) project. Journal of Hydrology, 282(1-4): 177-181.

Fan Jie, Li Pingxing, 2009. The scientific foundation of major function oriented zoning in China. Journal of Geographical Sciences, 19(5): 515-531.

Fresco LO, Leemans R, Van Zeijl-Rozema AE, 1996. Land use and cover change (LUCC) open science meeting Royal Netherlands Academy of Arts and Sciences, Amsterdam, The Netherlands, 29-31 January 1996. Land Use Policy, 13(4): 332-334.

Gao Peng, Niu Xiang, Wang Bing et al., 2015. Land use changes and its driving forces in hilly ecological restoration area based on GIS and RS of northern China. Scientific Reports, 5: 11038. doi: 10.1038/srep11038.

General Office of the State Council (GOSC), 2010. ([2010] No.46). Major Functional Area Planning in China.

Graetz D, 1993. Land cover: Trying to make the task tractable! In: Proceeding of the Workshop on Global Land Use/Cover Modelling. New York.

Haberl H, Erb K H, Krausmann F et al., 2007. Quantifying and mapping the human appropriation of net primary production in earth's terrestrial ecosystems. Proceedings of the National Academy of Sciences, 104(31): 12942-12947.

Hou Lizhu, Feng Shaoyuan, Ding Yueyuan et al., 2006. Runoff-rainfall relationship for multilayer infiltration systems under artificial rainfalls. Transactions of the CSAE, 22(9):100-105. (in Chinese)

$\mathrm{Hu}$ Zhibin, He Xingyuan, Li Yuehui et al., 2007. Human activity intensity and its spatial distribution pattern in upper reach of Minjiang River. Chinese Journal of Ecology, 26(4): 539-543. (in Chinese)

IPCC, 2014. Climate Change: Synthesis Report. Working Groups I, II and III Contribution to the 5th Assessment Report.

Jäger J, 2003. The International Human Dimensions Programme on global environmental change (IHDP). Global Environmental Change, 13(1): 69-73.

Leemans R, Asrar G, Busalacchi A et al., 2009. Developing a common strategy for integrated global change research and outreach: The Earth System Science Partnership (ESSP). Current Opinion in Environmental Sustainability, 1(1):4-13.

Li Xiangyun, Wang Lixin, Zhang Yushu et al., 2004. Analysis of roles of human activities in land desertification in arid area of Northwest China. Scientia Geographica Sinica, 24(1): 68-75. (in Chinese)

Li Xiubin, 1996. A review of the international researches on land use/cover change. Acta Geographica Sinica, 51(6): 553-557. (in Chinese)

Liu Jiyuan, Deng Xiangzheng, 2009. Development of research method of LUCC spatio-temporal process. Chinese Science Bulletin, 54(21): 3251-3258. (in Chinese)

Liu Yanhua, Ge Quansheng, Fang Xiuqi et al., 2006. Global environmental change and the national security of China. Advance in Earth Sciences, 21(4): 346-351. (in Chinese)

Liu Zhenhuan, Li You, Peng Jian, 2011. Progress and perspective of the research on hydrological effects of urban impervious surface on water environment. Progress in Geography, 30(3): 275-281. (in Chinese)

Loreau M, Olivieri I, 1999. Diversitas: An international programme of biodiversity science. Trends in Ecology \& Evolution, 14(1): 2-3.

Mauser W, Klepper G, Rice M et al., 2013. Transdisciplinary global change research: The co-creation of knowledge for sustainability. Current Opinion in Environmental Sustainability, 5(3/4): 420-431.

McGill B, 2015. Biodiversity: Land use matters. Nature, 520(7545): 38-39.

Miler R B, 1994. Interactions and collaboration in global change across the social and natural sciences. IMBIO, 
23(1): 19-24.

Mottet A, Ladet S, Coque $\mathrm{N}$ et al., 2006. Agricultural land-use change and its drivers in mountain landscapes: A case study in the Pyrenees. Agriculture, Ecosystems \& Environment, 114(2-4): 296-310.

Pelorosso R, Leone A, Boccia L, 2009. Land cover and land use change in the Italian central Apennines: A comparison of assessment methods. Applied Geography, 29(1):35-48.

Rees W E, 2001. Ecological footprint, concept of. Encyclopedia of Biodiversity, 2: 229-244.

Sekiya A, Okamoto S, 2010. Evaluation of carbon dioxide equivalent values for greenhouse gases: CEWN as a new indicator replacing GWP. Journal of Fluorine Chemistry, 131(3): 364-368.

She D, Gao X, Fang K, 2014. Measurement of soil sorptivity rate under different land uses by disc infiltrometer. Transactions of the CSAE, 30(18): 151-158. (in Chinese)

Shi Peijun, Li Ning, Ye Qian et al., 2009. Research on global environmental change and integrated disaster risk governance. Advance in Earth Sciences, 24(4): 428-435. (in Chinese)

Tang Huajun, Wu Wenbin, Yang Peng et al., 2009. Recent progresses of land use and land cover change (LUCC) models. Acta Geographica Sinica, 64(4): 456-468. (in Chinese)

Turner II B L, Lambin EF, Reenberg A, 2007. The emergence of land change science for global environmental change and sustainability. Proceedings of the National Academy of Sciences, 104(52): 20666-20671.

Turner II B L, Skole D, Sanderson S et al., 1995. Land-use and land-cover change science/research plan. IGBP Report No.35 and HDP Report No.7. Stockholm: IGBP.

US-SGCR/CENR. Our changing plant, the FY 1996 U.S. global change research program. Washington, D.C.: US-GCRIO, 1996.

Vitousek P M, Mooney H A, Lubchenco J et al., 1997. Human domination of Earth's ecosystems. Science, 277(5325): 494-499.

Wackernagel M, Rees W E, 1997. Perceptual and structural barriers to investing in natural capital: Economics from an ecological footprint perspective. Ecological Economics, 20(1): 3-24.

Wang Guisheng, Xie Yaowen, Wang Xueqiang, 2013. Evaluation on human activity in the middle reaches of Heihe River in historical period: A case study on the Ming Dynasty, Qing Dynasty and the Republic of China. Journal of Desert Research, 33(4): 1225-1234. (in Chinese)

Wang Hongjie, Li Xianwen, Shi Xuezheng et al., 2003. Distribution of soil nutrient under different land use and relationship between soil nutrient and soil granule composition. Journal of Soil and Water Conservation, 17(2): 44-46, 50. (in Chinese)

Wang Jinzhe, Zhang Guanghui, Nie Zhenlong et al., 2009. Quantitative assessment of human activity intensity in Hutuohe catchment. Journal of Arid Land Resources and Environment, 23(10): 41-44. (in Chinese)

Wen Ying, 1998. Preliminary discussion on the method of quantitative assessment of human activity intensity. Impact of Science on Society, (4): 55-60. (in Chinese)

Wu Chuanjun, Guo Huancheng, 1994. Chinese Land Use. Beijing: Science Press.

Xu Zhigang, Zhuang Dafang, Yang Lin, 2009. Construction and application of regional quantitative model of human activity intensity. Journal of Geo-information Science, 11(4): 452-460. (in Chinese)

Ye Duzheng, Fu Congbin, Ji Jinjun et al., 2001. Orderly human activities and subsistence environment. Advance in Earth Sciences, 16(4): 453-460. (in Chinese)

Yu Weiqing, Wang Yujie, Hu Haibo et al., 2014. Soil water infiltration characteristics analysis under different vegetation on the hilly ground of Yangtze River Delta. Chinese Journal of Soil Science, 45(2): 345-351. (in Chinese)

Zhang Cuiyun, Wang Zhao, 2004. Quantitative assessment of human activity intensity in the Heihe catchment. Advance in Earth Sciences, 19(Suppl.): 386-390. (in Chinese)

Zheng Wenwu, Tian Yaping, Zou Jun et al., 2010. Spatial simulation of human activity intensity in hilly red soil region of southern China: A case study in Hengyang basin, Hunan Province. Journal of Geo-information Science, 12(5): 628-633. (in Chinese)

Zhu Chunyang, Li Fang, Li Shuhua, 2009. Research on the influence of different pavement structures in landscape path on rainfall infiltration process. Chinese Landscape Architecture, (3): 91-97. (in Chinese)

Zhu Huiyi, Li Xiubin, 2003. Discussion on the index method of regional land use change. Acta Geographica Sinica, 58(5): 643-650. (in Chinese)

Zhuang Dafang, Liu Jiyuan, 1997. Study on the model of regional differentiation of land use degree in China. Journal of Natural Resources, 12(2): 105-111. (in Chinese) 